\title{
Genetic Mapping of the Scab Resistance Gene in Cucumber
}

\author{
Shengping Zhang ${ }^{1}$, Han Miao ${ }^{1}$, Xing-fang $\mathrm{Gu}^{2}$, Yuhong Yang, Bingyan Xie, Xiaowu Wang, \\ Sanwen Huang, Yongchen Du, and Rifei Sun \\ Institute of Vegetables and Flowers, Chinese Academy of Agricultural Sciences, Beijing 10081 China \\ Todd C. Wehner \\ Department of Horticultural Science, North Carolina State University, Raleigh, NC 27695-7609
}

\begin{abstract}
AdDitional IndEX words. Cucumis sativus, Ccu, SSR, marker-assisted selection, MAS
Abstract. Scab, caused by Cladosporium cucumerinum Ell. et Arthur, is a prevalent disease of cucumber (Cucumis sativus L.) worldwide. Scab can cause serious losses for cucumber production, especially in protected culture such as high tunnel production. Resistance to cucumber scab is dominant and is controlled by a single gene, $\mathrm{Ccu}$. Breeding for resistant cultivars is the most efficient way to control the disease. Selection for resistance might be made easier if the gene were mapped to linked markers. Thus far, there are no tightly linked (genetic distance less than $1 \mathrm{cM}$ ) simple sequence repeat (SSR) markers for the $C c u$ gene, and no studies on mapping of the $C c u$ gene in cucumber using SSR markers. The objective of this study was to identify SSR markers for use in molecular breeding of scab resistance. In this study, we used a population of recombinant inbred lines (RILs). The population included 148 individuals derived from the cucumber inbred line $9110 \mathrm{Gt}($ Сси Ccu) crossed with line 9930 ( $с с и с c u)$. The $C$ си gene was mapped to linkage group 2, corresponding to chromosome 2 of cucumber. The flanking markers SSR03084 and SSR17631 were linked to the $C с u$ gene with distances of 0.7 and $1.6 \mathrm{cM}$, respectively. The veracity of SSR03084 and SSR17631 was tested using 59 diverse inbred lines and hybrids, and the accuracy rate for the two markers was $98.3 \%$. In conclusion, two SSRs closely linked to scab resistance gene $C c u$ have been identified and can be used in a cucumber breeding program.
\end{abstract}

Scab is a prevalent disease of cucumber worldwide. Scab can cause serious losses for cucumber production, especially in protected culture such as high tunnel production (Lee et al., 1997; Mao et al., 2008; Rego, 1994). Resistance to cucumber scab is dominant and is controlled by a single gene, Ccu (AbulHayja et al., 1975; Andeweg, 1956; Bailey and Burgess, 1934; Vakalounakis, 1993; Wehner, 2005). Researchers have reported on methods of identification (Xu and Zhu, 1994), mechanisms of pathogenicity ( $\mathrm{Li}$ et al., 2001, 2008), and techniques for control (Li et al., 1998; Yuan, 1989) of cucumber scab. Genetic linkage of $\mathrm{Ccu}$ with other traits has also been studied (Mao et al., 2008; Vakalounakis, 1993; Vakalounakis and Klironomou, 1994). However, there are only a few reports on the molecular biology of scab on cucumber. Zhang et al. (2006) screened the amplified fragment length polymorphism (AFLP) marker, E20M64, linked to the $\mathrm{Ccu}$ gene, and reported a genetic distance of $4.83 \mathrm{cM}$. Sun et al. (2006) reported a simple sequence repeat (SSR) primer, CSWCT02B, that was linked to the $\mathrm{Ccu}$ gene with genetic distance of $28.7 \mathrm{cM}$. Bradeen et al. (2001) identified one restricted fragment length polymorphism (RFLP) marker, CMTC51 (0.5 cM), and one AFLP marker, E14M49-F-158-P2 (1.9 cM), linked to the $C c u$ gene using wide-based, merged maps. Thus far, no linkage of

Received for publication 14 Oct. 2009. Accepted for publication 24 Nov. 2009. The research was supported by the earmarked fund for Modern Agroindustry Technology Research System, by the Chinese Ministry of Agriculture (948 Program: 2008-Z42), by the Ministry of Science and Technology (2008BADB1B05, 973 program: 2009CB119004, 2006AA100108, 2006AA10Z1A8), and by the Key Laboratory of Horticultural Crops Genetic Improvement, Ministry of Agriculture.

${ }^{1}$ These authors contributed equally to this work.

${ }^{2}$ Corresponding author. E-mail: guxf@mail.caas.net.cn.
SSR markers to the $C c u$ gene has been reported, and no SSR marker with genetic distance less than $1 \mathrm{cM}$ to the $C c u$ gene in cucumber has been identified.

Scab can be efficiently controlled using resistant cultivars. Breeding for resistance was reported as early as 1934, but breeding work has continued throughout the world (Andeweg, 1956; Bailey and Burgess, 1934; Cavatorta et al., 2007; Li and Feng, 1994). However, phenotypic selection for scab resistance is difficult due to the large influence of environmental factors on development of the disease, and may require tests with multiple replications and years. Given these difficulties, cucumber breeders would benefit from a more efficient and more reliable scab resistance breeding procedure such as marker-assisted selection (MAS). With MAS, selection is on the marker rather than the disease rating.

An efficient MAS system requires markers having tight linkage to $C c u$, but combined with an assay that is easy to run. In previous studies, the markers linked to $C c u$ were RFLP and AFLP types, which are expensive, time consuming to measure, and involve the use of radioactive materials. Those marker types are not cost-efficient to use in molecular breeding. However, SSR markers are polymerase chain reaction (PCR)-based markers with codominant inheritance that are effective and easy to use in a breeding program. Development of SSR markers requires an investment before they can be used because genomic sequences have to be determined before primers can be designed and then used for mapping. Fortunately, the Cucumber Genome Initiative (CUGI), aimed at sequencing the genome of cucumber, was sponsored in China in 2007. Over 2000 pairs of highly polymorphic SSR markers from whole genome shotgun sequences were developed (Ren et al., 2009). In this article, a study of genetic mapping of the $C c u$ gene was 
Table 1. Disease reaction of 59 diverse cucumber inbred lines and hybrids used to test the flanking markers linked to $C c u$ gene. Thirteen inbred lines and hybrids (D7, D13, D16, D28, D31, D32, D33, D34, D37, D38, D39, D57, and D58) were identified to be resistant (R), and the rest of 46 inbred lines and hybrids to be susceptible (S).

\begin{tabular}{|c|c|c|c|c|}
\hline Code & Accession & Source & Ecotype & $\mathrm{S}$ or $\mathrm{R}$ \\
\hline$\overline{\mathrm{D} 1}$ & Zhongnong No. 8 & China & Northern China type & S \\
\hline D3 & Zhongnong No. 10 & China & Northern China type & $\mathrm{S}$ \\
\hline D5 & Zhongnong No. 15 & China & Japanese type & $\mathrm{S}$ \\
\hline D6 & Zhongnong No. 16 & China & Northern China type & S \\
\hline D7 & Zhongnong No. 19 & China & European greenhouse type & $\mathrm{R}$ \\
\hline D10 & Zhongnong No. 106 & China & Northern China type & S \\
\hline D11 & 06W8 & China & Northern China type & S \\
\hline D12 & 06W2 & China & Northern China type & $\mathrm{S}$ \\
\hline D13 & 06W12 & China & Hybrid of northern China type and European type & $\mathrm{R}$ \\
\hline D14 & 06P32 & China & Southern China type & S \\
\hline D19 & 228 & China & Northern China type & $\mathrm{S}$ \\
\hline D20 & 05590 & China & Northern China type & S \\
\hline D21 & 01316 & China & Northern China type & S \\
\hline D22 & 05603 & China & Uncertain & $\mathrm{S}$ \\
\hline D23 & 04939 & China & Northern China type & $\mathrm{S}$ \\
\hline D24 & 05939 & China & Northern China type & $\mathrm{S}$ \\
\hline D25 & 04348 & China & Northern China type & $\mathrm{S}$ \\
\hline D26 & 0227 & China & Northern China type & $\mathrm{S}$ \\
\hline D27 & 05905 & China & Northern China type & $\mathrm{S}$ \\
\hline D28 & 06469 & China & European greenhouse type & $\mathrm{R}$ \\
\hline D29 & 183 & Japan & Japanese type & $\mathrm{S}$ \\
\hline D30 & 185 & Japan & Japanese type & S \\
\hline D38 & 05950 & China & Southern China type & $\mathrm{R}$ \\
\hline D39 & 05909 & China & Hybrid of northern China type and European type & $\mathrm{R}$ \\
\hline D40 & 05914 & China & Uncertain & S \\
\hline D41 & 03486G & China & Northern China type & S \\
\hline D42 & 05952 & China & Southern China type & S \\
\hline D43 & 04870 & China & Southern China type & S \\
\hline D44 & 05403 & China & Northern China type & S \\
\hline D45 & 05372 & China & Northern China type & S \\
\hline D46 & 05641 & China & Northern China type & S \\
\hline D47 & 05634 & China & Northern China type & S \\
\hline D48 & 06123 & China & Northern China type & S \\
\hline D49 & 18930 & China & Northern China type & S \\
\hline D50 & 06958 & China & Northern China type & S \\
\hline D51 & 06959 & China & Northern China type & S \\
\hline D52 & Xintai mici & China & Northern China type & S \\
\hline D53 & Jinyan No.2 & China & Northern China type & S \\
\hline D54 & Zhongnong No. 21 & China & Northern China type & S \\
\hline D55 & Zhongnong No. 27 & China & Northern China type & S \\
\hline D56 & 0313 & China & Northern China type & S \\
\hline D57 & Marketmore 76 & U.S. & American slicing type & $\mathrm{R}$ \\
\hline D58 & Manteo & U.S. & American processing type & $\mathrm{R}$ \\
\hline D59 & Xishuangbanna cucumber & China & Southern Asian type & S \\
\hline
\end{tabular}


conducted and SSR markers for the $C c u$ gene were identified that had tight linkage. Those SSR markers have been used in the selection of resistant germplasm.

\section{Materials and Methods}

MaPPing POPUlations. We used $148 \mathrm{~F}_{9}$ recombinant inbred lines (RILs) to map the $\mathrm{Ccu}$ gene. RILs were derived from the cross of two elite inbred lines, $9110 \mathrm{Gt} \times 9930$. Inbred $9110 \mathrm{Gt}$ is resistant to cucumber scab, and was derived from a cross of a European greenhouse line with a northern Chinese line. Inbred 9930 is susceptible to scab, and is a northern Chinese type for which the genome had been sequenced.

Disease Resistance screen. The degree of resistance to cucumber scab for the RILs was tested in May 2007 and Dec. 2008 using an artificial inoculation method. The method involved soaking seeds in 5\% sodium hypochlorite for 10 min, washing with tap water, and placing in a petri dish having two layers of filter paper pad for germination in incubator under the constant temperature of $28^{\circ} \mathrm{C}$. When the radicle was $5 \mathrm{~mm}$ long, the seeds were sown individually into plastic pots filled with steam-sterilized propagation substrates. Propagation substrate was composed of peat, vermiculite, and soil from vegetable fields (2:1:1, volume basis) and was steam sterilized at $134{ }^{\circ} \mathrm{C}$ for $30 \mathrm{~min}$. Seedlings were placed in a growth chamber held at $25 / 20^{\circ} \mathrm{C}$ day/night with a 16 -h photoperiod. Illumination was provided by high-pressure sodium lamps at $50 \mathrm{~W} \cdot \mathrm{m}^{-2}$.

Identification materials were arranged randomly with three replications of 10 plants each. Resistant cultivar Zhongnong No. 13 and susceptible cultivar Jinza No. 4 were used as controls. All seedings were inoculated, at the stage of fully open first true leaf, with a single strain of Cladosporium cucumerinum. Both sides of the leaves of the seedlings were sprayed uniformly using a hand-pumped sprayer to the point of leaf runoff. Inoculation concentration was $2 \times 10^{6}$ spores $/ \mathrm{mL}$. After inoculation, plants were kept in the dark at $100 \%$ relative humidity (RH) for $24 \mathrm{~h}$, followed by 7 to $10 \mathrm{~d}$ at $60 \% / 85 \% \mathrm{RH}$ (day/night) at temperatures of 20 to $23^{\circ} \mathrm{C}$.

Symptom ASSESSMent. Disease resistance was rated 7 to $10 \mathrm{~d}$ after inoculation, and a disease index (DI), a weighted mean, was calculated according to the formula:

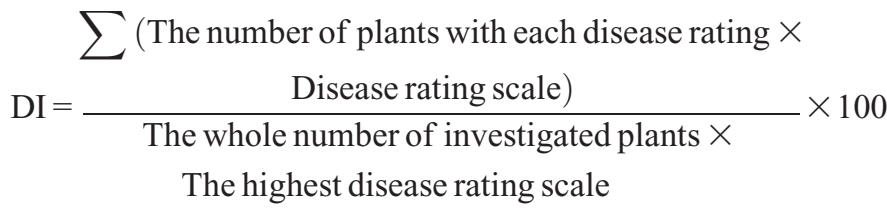

The disease rating scale was as follow: $0=$ absence of disease symptoms; 1 = few disease spots on leaf and no spots on stem; 2 = petiole shriveled, few disease spots on leaf, and small spots on stem; 3 = petiole shriveled, center of leaf wilted, sunken disease spots on stem; 4 = petiole shriveled, center of leaf dry and wilted, and sunken disease spots on stem; $5=$ petiole and leaf dry and wilted and shrunken disease spots on stem. Scab resistance for each plant was determined using the DI. When the disease susceptible control (Jinza No. 4) reached DI $>45$, the evaluation of identification efficiency was made. Seedlings rated $0<\mathrm{DI} \leq 15$ were considered to be highly resistant, $15<\mathrm{DI} \leq 30$ were considered to be resistant, $30<\mathrm{DI}$ $\leq 45$ were considered to be moderately resistant, $45<\mathrm{DI} \leq 65$ were considered to be susceptible, and $65<$ DI were considered to be highly susceptible.

SSR MARKER ANALYSIS. DNA was extracted from young leaf tissue of the parental lines, $F_{1}$, and each plant in the population of RILs using a CTAB extraction procedure (Maniatis et al., 1982; Staub et al., 1996a). DNA concentration was estimated on a $1 \%$ agarose gel with $1 \times$ TEA buffer stained with ethidium bromide.

Each $15 \mu \mathrm{L}$ of the PCR reaction mix contained $8.02 \mu \mathrm{L}$ of double-distilled water $\left(\mathrm{ddH}_{2} \mathrm{O}\right), 1.5 \mu \mathrm{L}$ of $10 \times$ buffer, $0.2 \mu \mathrm{L}$ of dNTPs $(10 \mathrm{~mm}), 0.08 \mu \mathrm{L}$ of Taq DNA polymerase $(10 \mathrm{U} / \mu \mathrm{L})$, $0.6 \mu \mathrm{L}$ of primer $\mathrm{F}\left(50 \mathrm{ng} \cdot \mu \mathrm{L}^{-1}\right), 0.6 \mu \mathrm{L}$ of primer $\mathrm{R}(50$ $\left.\mathrm{ng} \cdot \mu \mathrm{L}^{-1}\right)$, and $4.0 \mu \mathrm{L}$ of DNA $\left(10 \mathrm{ng} \cdot \mu \mathrm{L}^{-1}\right)$. The PCR amplifications were performed using a GeneAmp PCR system 9700 (Applied Biosystems, Foster City, CA) as follows: $94^{\circ} \mathrm{C} / 4 \mathrm{~min}$, 35 cycles of $94^{\circ} \mathrm{C} / 15 \mathrm{~s}, 55^{\circ} \mathrm{C} / 15 \mathrm{~s}, 72^{\circ} \mathrm{C} / 30 \mathrm{~s}$, and $72^{\circ} \mathrm{C} / 5 \mathrm{~min}$, $16^{\circ} \mathrm{C}$. Subsequently, $3 \mu \mathrm{L}$ of the PCR product was employed for electrophoresis in a $6 \%$ polyacrylamide gel according to the method used by Sambrook and Russell (2001).

A total of 2531 pairs of SSR primers were screened to identify polymorphisms between the parental lines (9110Gt and 9930) of the RIL population. The development of the SSR primers used in this study was described by Ren et al. (2009). PCRs using identified polymorphic SSR primers were conducted on DNA from individual plants of the RILs to collect data for genetic mapping analysis.

Genetic MAPPING. JoinMap program (version 3.0; Van Ooijen and Voorrips, 2001) was used to develop linkage maps. Marker segregation was analyzed for conformation to Mendelian ratios expected in the RILs using a chi-square test. A minimum logarithm of odds (LOD) of 4.0 was set as a threshold to relegate marker loci into linkage groups, to order markers, and to estimate interval distances (Kosambi function).

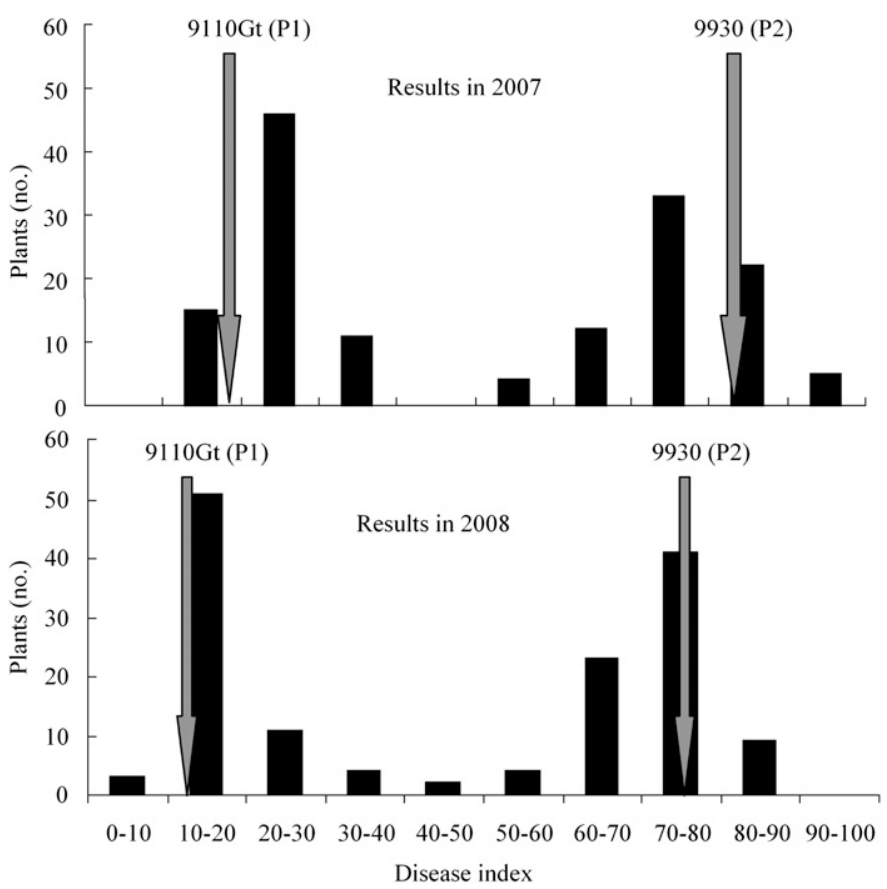

Fig. 1. Frequency distributions of disease index to cucumber scab in the $9110 \mathrm{Gt}$ $\times 9930$ cucumber recombinant inbred line population during 2007 and 2008 . The parental line [9110Gt (susceptible) and 9930 (resistant)] values of disease index were indicated by arrows. 
Table 2. Segregation ratios of resistance to cucumber scab in the $9110 \mathrm{Gt} \times 9930$ cucumber recombinant inbred line (RIL) population during 2007 and 2008. The segregation of resistance and susceptibility fit a ratio of $1: 1$.

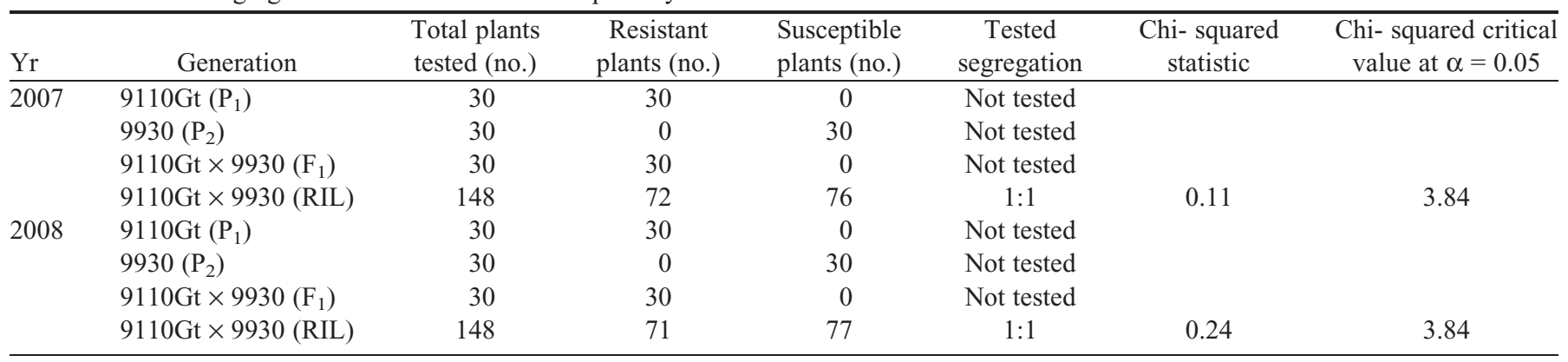

TeSt OF FLANKING SSR MARKERS LINKEd TO CCU GENE. We used 59 diverse inbred lines and hybrids to test the veracity of flanking SSR markers linked to the $\mathrm{Ccu}$ gene. They included the northern Chinese type, southern Chinese type, European greenhouse type, American processing type, American slicing type, southern Asian type, Japanese type, and hybrids of northern Chinese type with European greenhouse type. Scab reaction had been measured previously, with 13 resistant and 46 susceptible (Table 1).

\section{Results}

CuCumber SCAB Resistance OF THE RILs. In the results for 2007, the DI for parental lines $9110 \mathrm{Gt}$ and 9930 were 17.5 and 83.6, respectively. The resistance of $9110 \mathrm{Gt}$ and the susceptibility of 9930 to cucumber scab were confirmed. The $F_{1}$ generation had a DI of 20.0, and was judged to be resistant. There were 72 plants in the RIL population resistant to cucumber scab with a DI $<45.0$, and 76 plants susceptible to cucumber with a DI $>45.0$ (Fig. 1). The segregation of resistance and susceptibility fit a ratio of 1:1 (Table 2).

In 2008, line $9110 \mathrm{Gt}$ had a DI $=12.8$ in the artificial inoculation, and was confirmed to be highly resistant to scab. The DIs for line 9930 and the $F_{1}$ generation were 76.9 and 20.0, respectively. There were 71 plants in the RIL population resistant to cucumber scab with a DI $<45.0$, and 77 plants susceptible to cucumber with a DI $>45.0$ (Fig. 1). The segregation of resistance and susceptibility fit a ratio of 1:1 (Table 2).

The results from 2007 and 2008 were consistent except for one line of RILs. This line was identified as moderately resistant with a DI of 38.9 in 2007 . However, it was rated susceptible with a DI of 45.7 in 2008 . The reason may be due to environmental conditions. Analysis of the data for parental lines, the $\mathrm{F}_{1}$ generation, and the RIL population confirmed that a single dominant gene controlled resistance to cucumber scab.

SSR MARKER ANALYSIS AND GENETIC MAPPING. Molecular analysis performed on $9110 \mathrm{Gt}$ and 9930 using the SSR method resulted in identification of 320 primers generating polymorphic amplicons from the total of 2531 pairs of SSR primers. The polymorphic rate was $12.6 \% ; 251$ SSR markers showed polymorphism in the RIL population. SSR markers linked with the Ccu gene based on JoinMap, version 3.0, were identified, and were found to be on cucumber chromosome 2 . There were 33 SSR loci and $C c u$ in the linkage group spanning $87.9 \mathrm{cM}$ of distance, with an average genetic interval of $2.59 \mathrm{cM}$. The shortest and the longest genetic intervals were 0.3 and $11.4 \mathrm{cM}$, respectively. The location of $\mathrm{Ccu}$ was at $77.4 \mathrm{cM}$, with flanking markers SSR03084 (R: CAG ACC CTG AAG CGG ATA AA;

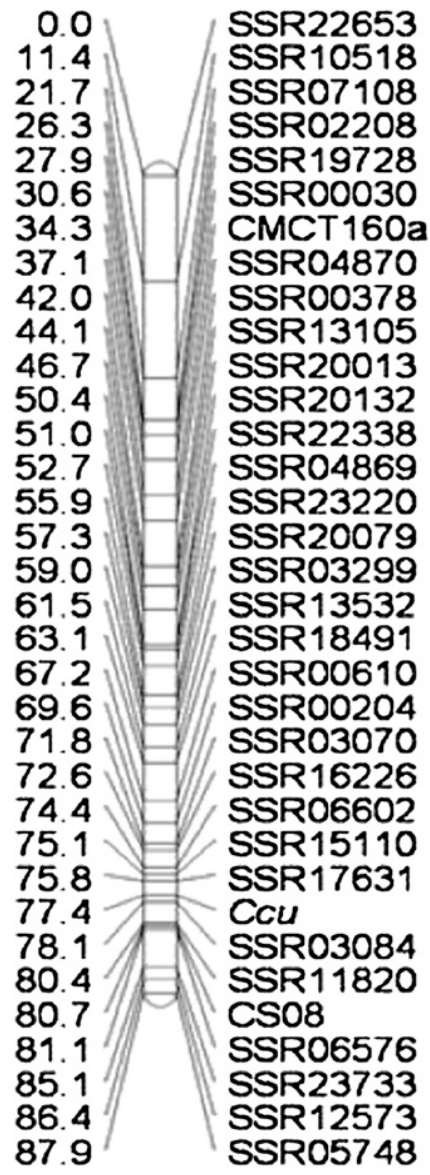

Fig. 2. Linkage of SSR markers to $C c u$ gene in cucumber mapped on chromosome 2. There were $33 \mathrm{SSR}$ loci and $\mathrm{Ccu}$ in the linkage group spanning $87.9 \mathrm{cM}$ of distance, with an average genetic interval of $2.59 \mathrm{cM}$. The location of $C c u$ was at $77.4 \mathrm{cM}$, with flanking markers SSR03084 and SSR17631 were linked to the $C c u$ gene with genetic distances of 0.7 and 1.6 $\mathrm{cM}$.

L: GAC AAG GGA TTC ATC CGA GA) and SSR17631 (R: TTC CCT AAG TAG TGA CGG ATT TTT; L: TTG ATT CCA ATT TCA TTA CTT TTC A) linked to the $C c u$ gene with genetic distances of 0.7 and $1.6 \mathrm{cM}$, respectively (Fig. 2).

Flanking Markers LINKed to $\boldsymbol{C} \boldsymbol{C U}$ Gene. The veracity of the two SSR markers SSR03084 and SSR17631 tightly linked to the $\mathrm{Ccu}$ gene was tested using 59 diverse inbred lines and hybrids. For SSR03084, there were 14 inbred lines and hybrids (D7, D13, D16, D28, D31, D32, D33, D34, D37, D38, D39, 
D56, D57, and D58) with the same band (about $195 \mathrm{bp}$ ) as resistant (maternal) parent $9110 \mathrm{Gt}$, and the rest of 45 inbred lines and hybrids with the same band (about $205 \mathrm{bp}$ ) as the susceptible (paternal) parent 9930 (Fig. 3). The result was identical to the artificial inoculation identification, except for D56. D56 was identified as susceptible to cucumber scab, but had the same special band (about $195 \mathrm{bp}$ ) as $9110 \mathrm{Gt}$. Thus, the accuracy rate for SSR03084 was $98.3 \%$. As for SSR17631, the result of SSR analysis for the 59 diverse inbred lines and hybrids was identical to the artificial inoculation identification, except for D4. D4 should have the same band (about 205 bp) as 9930, but it had the same band (about $195 \mathrm{bp}$ ) as 9110Gt. Thus, the accuracy rate for SSR17631 was also 98.3\%. Therefore, SSR03084 and SSR17631 were reliable SSR markers to be used to screen cucumber scab resistance resources in molecular breeding.

\section{Discussion}

In cucumber, many important disease resistance traits are inherited as single genes (Pierce and Wehner, 1990). Cucumber scab resistance is controlled by a single dominant gene (AbulHayja et al., 1975; Andeweg, 1956; Bailey and Burgess, 1934; Vakalounakis, 1993; Wehner, 2005). This study confirmed the previously published conclusion with the expected 1:1 segregation ratio in a RIL population.

There was one line of the RILs that was identified as moderately resistant, with a DI of 38.9 in 2007 and was identified as susceptible with DI of 45.7 in 2008. This line had a band (about 190 bp) consistent with maternal line 9110Gt (resistant to cucumber scab) by the SSR analysis. Thus, this line should be resistant to cucumber scab. Environmental conditions may have changed its reaction in 2008.

The use of molecular markers for selection in cucumber is difficult because of its narrow genetic base. The level of polymorphism in commercial cucumber is low (Kennard et al., 1994), similar to self-pollinated (Apuya et al., 1988; Helentjaris et al., 1986) rather than cross-pollinated species (Figdore et al., 1988; Helentjaris et al., 1986). In this study, the rate of polymorphism was $12.6 \%$ in $9110 \mathrm{Gt}$ and 9930. Among the cucumber disease resistance traits already mapped are resistances to downy mildew [Pseudoperonospora cubensis (Horejsi et al., 2000)] and to zucchini yellow mosaic virus (Park et al., 2000). We screened SSR markers SSR03084 (0.7 cM) and SSR17631 $(1.6 \mathrm{cM})$ that were tightly linked to the cucumber scab resistance gene $\mathrm{Ccu}$, and $\mathrm{Ccu}$ was mapped onto chromosome 2 of cucumber. SSR03084 has the smallest genetic distance from $\mathrm{Ccu}$ of any SSR marker identified thus far.

MAS efficiency depends on the recombination fraction and linkage phase of the marker to the target gene (Staub et al., 1996b). MAS is more efficient when using flanking rather than single markers (Horejsi et al., 2000). The flanking markers SSR03084 and SSR17631 reported here have the potential for use in MAS. The veracity of the two SSR markers was tested using 59 inbred lines and hybrids. The accuracy rates for SSR03084 and SSR17631 were the same, at 98.3\%. If the two markers were used together in MAS, the accuracy rate would be increased to $98.9 \%$. SSR analysis was also conducted for the 148 RIL population using SSR03084 and SSR17631. As for SSR03084, the result was identical to the artificial inoculation identification, except for one line, and the accuracy rate was $99.3 \%$. However, there were six lines with a result not identical to the DI when SSR analysis was conducted using SSR17631. Thus, the accuracy rate decreased to $95.9 \%$ for SSR17631 in the RIL population. The reason was related to the genetic distance between the SSR marker and the $\mathrm{Ccu}$ gene. If both SSRs were used to analyze the 148 RIL population, the accuracy rate would increase to $100 \%$. Thus, better correlation to disease resistance can be got when both SSRs are used. These markers will be used in marker-assisted breeding projects and for map-based cloning of the resistance gene.

\section{Literature Cited}

Abul-Hayja, Z., P.H. Williams, and E.D.P. Whelan. 1975. Independence of scab and bacterial wilt resistance and ten seedling markers in cucumber. HortScience 10:423-424.

Fig. 3. SSR analysis for 59 diverse cucumber inbred lines and hybrids using SSR03084. The polymorphic amplicon of $195 \mathrm{bp}$ was present in resistant lines and $9110 \mathrm{Gt}$, whereas the polymorphic amplicon of $205 \mathrm{bp}$ was in susceptible lines and 9930. Lane M: DNA molecular weight marker (fragment lengths are given in bps); Lane P1: resistant line 9110Gt, 195-bp amplicon present; Lane P2: susceptible line 9930, 205-bp amplicon present; Lane 1 to Lane 42: D1 to D42; Lane 43: blank; Lane 44 to Lane 59: D43 to D58; Lane 60: blank; Lane 61: D59; 195-bp amplicon was present in D7, D13, D16, D28, D31, D32, D33, D34, D37, D38, D39, D56, D57, D58; $205-$ bp amplicon was present in the rest of the 45 materials. The two arrows indicate the 195 -bp amplicon.
Andeweg, J.M. 1956. The breeding of scab-resistant frame cucumbers in the Netherlands. Euphytica 5:185-195.

Apuya, N., B.L. Frazier, P. Keim, E.J. Roth, and K.G. Lark. 1988. Restriction 
fragment length polymorphisms as genetic markers in soybean, Glycine $\max$ (L.). Merr. Theor. Appl. Genet. 75:889-901.

Bailey, R.M. and I.M. Burgess. 1934. Breeding cucumbers resistant to scab. Proc. Amer. Soc. Hort. Sci. 32:474-476.

Bradeen, J.M., J.E. Staub, and C. Wye. 2001. Towards an expanded and integrated linkage map of cucumber (Cucumis sativus L.). Genome 44:111-119.

Cavatorta, J., G. Moriarty, and M. Henning. 2007. 'Marketmore 97': A monoecious slicing cucumber inbred with multiple disease and insect resistances. HortScience 42:707-709.

Figdore, S.S., W.C. Kennard, K. Song, M. Slocum, and T.C. Osborn. 1988. Assessment of the degree of restriction fragment length polymorphism in Brassica. Theor. Appl. Genet. 75:833840 .

Helentjaris, T., M. Slocum, S. Wright, A. Schaefer, and J. Nienhuis. 1986. Construction of genetic linkage maps in maize and tomato using restriction fragment length polymorphisms. Theor. Appl. Genet. 72:761-769.

Horejsi, T., J.E. Staub, and C. Thomas. 2000. Linkage of random amplified polymorphic DNA markers to downy mildew resistance in cucumber (Cucumis sativus L.). Euphytica 115:105-113.

Kennard, W.C., K. Poetter, A. Dijkhuizen, V. Meglic, J. Staub, and M. Havey. 1994. Linkages among RFLP, RAPD, isozyme, disease resistance, and morphological markers in narrow and wide crosses of cucumber. Theor. Appl. Genet. 89:42-48.

Lee, K.Y., K.H. Young, and H.J. Kang. 1997. Cucumber scab caused by Cladosporium cucumerinum in Korea. Korean J. Plant Pathol. 13:288-294.

Li, B.D. and D.X. Feng. 1994. Primary resistance screening report to scab in cucumber varieties. Plant Protection 1:20-23. (in Chinese).

Li, B.J., C.L. Zhou, and K.H. Zhao. 2001. Pathogenic mechanism of scab of cucumber caused by Cladosporium cucumerinum. Acta Phytopathologica Sin. 31:62-69. (in Chinese).

Li, B.J., X.M. Liu, and X.W. Peng. 2008. Screening of incompatible isolate of Cladosporium cucumerinum with heat-resistance and its inducing disease-resistance in cucumber. Acta Hort. Sinica 35:363370. (in Chinese).

Li, F.Y., B.J. Li, and Z.Y. Miao. 1998. Study on control technique to scab in cucumber. Liaoning Agr. Sci. 1:8-10. (in Chinese).

Maniatis, T., E.F. Fritsch, and J. Sambrook. 1982. Molecular cloning: A laboratory manual. Cold Spring Harbor Laboratory Press, Cold Spring Harbor, NY.

Mao, A.J., F. Zhang, and L.R. Zhang. 2008. Analysis on the inheritance of resistance to Fusarium wilt race 4 and cucumber scab and their linkage in cucumber WIS2757. Sci. Agr. Sinica 41:33823388. (in Chinese).

Park, Y.H., S. Sensoy, C. Wye, R. Antonise, J. Peleman, and M.J. Havey. 2000. A genetic map of cucumber composed of RAPDs, RFLPs, AFLPs, and loci conditioning resistance to papaya ringspot and zucchini yellow mosaic viruses. Genome 43:1003-1010.

Pierce, L.W. and T.C. Wehner. 1990. Review of genes and linkage groups of cucumber. HortScience 25:605-615.

Rego, A.M. 1994. Diseases caused by fungi on Cucurbitaceae. Informe Agropecuario (Belo Horizonte) 17:48-54.

Ren, Y., Z. Zhang, and J. Liu. 2009. An integrated genetic and cytogenetic map of the cucumber genome. PLoS One 4:1-8.

Sambrook, J. and D.W. Russell. 2001. Molecular cloning: A laboratory manual. 3rd ed. Cold Spring Harbor Laboratory Press, Cold Spring Harbor, NY.

Staub, J.E., F.C. Serquen, and M. Gupta. 1996b. Genetic markers, map construction, and their application in plant breeding. HortScience 31:729-741.

Staub, J.E., J. Bacher, and K. Poetter. 1996a. Sources of potential errors in the application of random amplified polymorphic DNAs in cucumber. HortScience 31:262-266.

Sun, X.H., S.L. Du, and G.H. Zhang. 2006. Polymorphism comparison of AFLP and SSR between scab resistant cucumber materials. Acta Agr. Boreali-Sinica 21:105-107. (in Chinese).

Vakalounakis, D.J. 1993. Inheritance and genetic linkage of Fusarium wilt (Fusarium oxysporum f. sp. cucumerinum race 1) and scab (Cladosporium cucumerinum) resistance genes in cucumber (Cucumis sativus). Ann. Appl. Biol. 123:359-365.

Vakalounakis, D.J. and E. Klironomou. 1994. Independence between scab resistance and morphological traits in cucumber. HortScience 29:1180-1181.

Van Ooijen, J. and R. Voorrips. 2001. JoinMap 3.0, software for calculation of genetic linkage maps. Plant Research International, Wageningen, The Netherlands.

Wehner, T.C. 2005. Gene list 2005 for cucumber. Cucurbit Genet. Coop. Rpt. 28-29:105-141.

Xu, Y. and Q.J. Zhu. 1994. Resistance identification method on scab resistance by inoculation excised cotyledon in cucumber. J. China Agr. Univ. 1:30-34. (in Chinese).

Yuan, M. 1989. The occurrence of cucumber scab and its control. Acta Agr. Univ. Jilinensis 11:7-13. (in Chinese).

Zhang, G.H., Y.K. Han, and X.H. Sunday. 2006. Molecular marker linked to the resistant gene of cucumber scab. Sci. Agr. Sinica 39:2250-2254. (in Chinese). 